\title{
Comparative activity of ampicillin and seven cephalosporins against group D streptococci
}

\author{
J. M. T. HAMILTON-MILLER
}

From the Department of Medical Microbiology, Royal Free Hospital, Pond Street, London NW3

SYNOPSIS Minimum inhibitory concentrations have been determined for ampicillin and seven cephalosporins against 93 strains of group D streptococci isolated recently from clinical material. Ampicillin was much the most active compound (modal MIC $=1.6 \mu \mathrm{g} / \mathrm{ml}$ ); cephaloridine, cephacetrile, and cefazolin had a modal MIC of $25 \mu \mathrm{g} / \mathrm{ml}$, while corresponding figures for cephalothin, cephradine, cephalexin, and cefoxitin were $50,100,200$, and $800 \mu \mathrm{g} / \mathrm{ml}$, respectively. Thus, none of the newer cephalosporins is an improvement in respect to activity against enterococci over existing compounds, and ampicillin remains overwhelmingly the $\beta$-lactam antibiotic of choice for the treatment of infections by such organisms. Pharmacokinetic considerations, however, indicate that certain cephalosporins, for instance, cephaloridine, cefazolin, and cephanone, may be worthy of further study in view of possible synergy with aminoglycoside antibiotics.

Strains of streptococci belonging to Lancefield group D, commonly called enterococci or faecal streptococci, differ markedly from other streptococci pathogenic to man by being relatively resistant to many commonly used antibiotics (Garrod, Lambert, and O'Grady, 1973). Thus, Toala, McDonald, Wilcox, and Finland (1969), who determined the sensitivities of some 382 strains of enterococci to 21 antibiotics, found that only ampicillin, benzylpenicillin, and vancomycin inhibited virtually all strains at a concentration of $6.3 \mu \mathrm{g} / \mathrm{ml}$. The advent of several new cephalosporins in the past few years (Hamilton-Miller and Brumfitt, 1974) has raised the question as to whether any of these newer compounds show useful activity against enterococci, especially in view of two recent reports. The first of these, by Isenberg, Painter, Sampson-Scherer, and Siegel (1973), suggests that, on the basis of disk tests, cephacetrile is considerably more active than cephalothin against group D streptococci, and the second is a statement (unsupported by any documentation) by Neiss (1973) that cephradine is more active than is cephalexin against enterococci. In view of the above, it was felt that a study of the antibacterial activity in vitro of established cephalosporins (cephalothin, cephaloridine, and cephalexin) in comparison with that of newer compounds (cefazolin, cephacetrile, cephradine, and cefoxitin),

Received for publication 19 June 1974. using ampicillin as reference compound, would hele to clarify the situation.

\section{Methods and Materials}

BACTERIAL STRAINS

These were taken from amongst isolates made from clinical material sent to the routine microbiology laboratory of this hospital. The series does not consist of consecutive isolates, but strains were taken at random over the course of about three months at the end of 1973 and the beginning of 1974 ; it can thus be regarded as representative of clinically isolated enterococci from a general hospital in Great Britain.

It is the practice in our laboratory to identify enterococci by virtue of their ability to grow well on agar containing $40 \%(w / v)$ bile (Facklam and Moody, 1970), and it was from such plates that the strains comprising this series were taken. The isolates came in roughly equal proportions from urine, high vaginal swabs, and wound swabs. They were first subcultured to MacConkey agar, and those showing characteristic pinpoint magenta colonies were entered as confirmed enterococci. Strains were speciated by virtue of their ability to grow in nutrient broth containing $6.5 \%(\mathrm{w} / \mathrm{v}) \mathrm{NaCl}$, their fermentative activity on sorbitol and arabinose, and growth in the presence of tellurite (Cowan and Steel, 1965). Strept. faecalis strains were further subdivided on 
the basis of their haemolytic activity and their action on gelatin-charcoal discs: gelatinase-negative, nonhaemolytic strains were classed as var faecalis; gelatinase-positive, non-haemolytic strains as var liquefaciens; and $\beta$-haemolytic, gelatinase-variable strains as var zymogenes (Cruickshank, 1968). Strains were stored on blood agar at $4^{\circ}$.

\section{MIC DETERMINATIONS}

Strains were inoculated into brain heart infusion (BHI) broth (Difco) containing 4\% (v/v) lysed horse blood, and incubated overnight at $37^{\circ}$. Cultures were diluted one hundred fold in water and plated on to BHI agar $+4 \%$ lysed horse blood containing serial doubling dilutions of antibiotic. Inoculation was performed using a multiple inoculating device which delivers some $3 \mu$ l each of 25 individual bacterial suspensions simultaneously from loops. Separate determinations indicated that about $16 \mathrm{ng}$ dry weight of each organism was inoculated. Taking the figures of Luria (1960) for the dimensions of Strept. faecalis and the density of dried bacteria, it can be calculated that this inoculum is equivalent to about $\mathbf{4 0 0 0 0}$ individual steptococci. The plates were incubated at $37^{\circ} \mathrm{C}$, and read after 18 and 42 hours.

Experience showed that the same result was obtained at both time intervals but that plates were much easier to read after 42 hours. Growth was scored as positive if more then one distinct colony was observed in an inoculation area; slight confluent growth and multiple microcolonies visible by both reflected and transmitted light were also scored as positive. Results were cumulated and processed to determine arithmetic mean, mode, and median value for each antibiotic, and also plotted on semilogarithmic paper to calculate, by interpolation, that concentration (C50) which would inhibit $50 \%$ of the strains.

\section{ANTIBIOTICS}

The following compounds were used: sodium ampicillin (Beecham Research Laboratories), cepha- loridine and cephalexin (Glaxo Research Laboratories), sodium cephalothin (Lilly Research Laboratories), cefazolin (Fujisawa Pharmaceuticals), cephacetilie (Ciba Pharmaceuticals), cephradine (Smith, Kline \& French Laboratories), and sodium cefoxitin (Merck, Sharp \& Dohme).

\section{Results}

CLASSIFICATION OF ORGANISMS

Of the 93 strains of group D streptococci isolated, most, 52 (56\%), were Strept. faecalis var faecalis; 23 $(24.7 \%)$ strains were var zymogenes (19 were gelatinase-negative), and $11(11.8 \%)$ var liquefaciens. The remaining seven strains were divided between Strept. faecium (2) and Strept. durans (5). These figures are in marked contrast to those reported from the Boston City Hospital (Toala et al, 1969), where the liquefaciens and zymogenes varieties together made up $72.5 \%$ of the total isolates; here the corresponding figure is $36.5 \%$.

\section{SENSITIVITIES TO AMPICILLIN AND CEPHALO- SPORINS}

The results are shown in table I and summarized in table II. As no clear-cut species differences were discernible, the data in table II are for all the strains. The close coincidence in the numerical values for the mean, mode, and median MIC for each antibiotic

\begin{tabular}{lcccc}
\hline Antibiotic & Mean & $\begin{array}{c}\text { Median } \\
(\mu \mathrm{g} / \mathrm{ml})\end{array}$ & Mode & C50 \\
\hline Cefoxitin & 741.1 & 800 & 800 & 540 \\
Cephalexin & 222.6 & 200 & 200 & 150 \\
Cephradine & 108.9 & 100 & 100 & 72 \\
Cephalothin & 42.3 & 50 & 50 & 30 \\
Cefazolin & 35.2 & 25 & 25 & 21 \\
Cephacetrile & 22.2 & 25 & 25 & 16 \\
Cephaloridine & 20.8 & 25 & 25 & 15 \\
Ampicillin & 1.9 & 1.6 & 1.6 & 1.25 \\
\hline
\end{tabular}

Table II Summary of antibiotic activity against enterococci

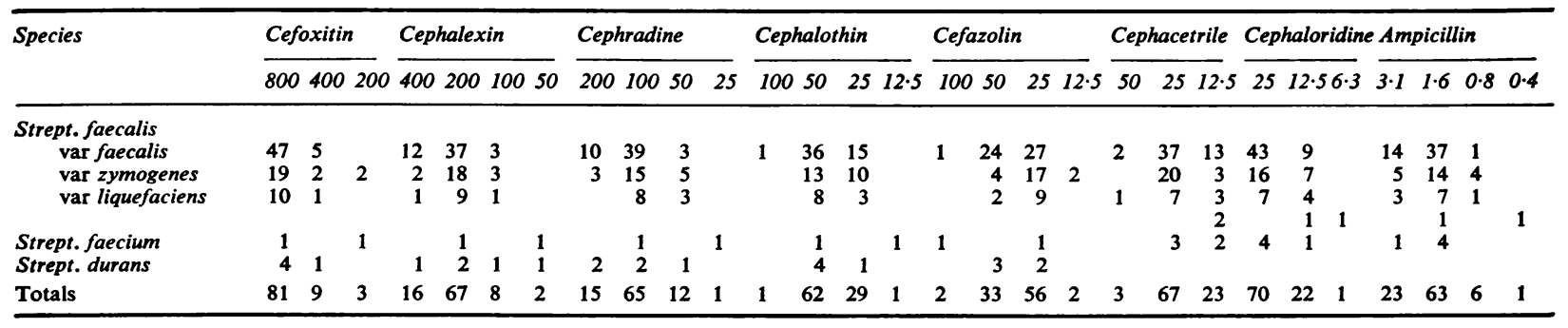

Table I Minimum inhibitory concentrations of eight antibiotics against enterococci ${ }^{1}$ ${ }^{2}$ Number of strains with indicated minimum inhibitory concentration $(\mu \mathrm{g} / \mathrm{ml})$ 


\begin{tabular}{|c|c|c|c|}
\hline Antibiotic & Route & $\begin{array}{l}\text { Mean Peak Serum Level } \\
(\mu \mathrm{g} / \mathrm{ml})\end{array}$ & Reference \\
\hline Cefazolin & Intramuscular & 64 & Gold et al (1973) \\
\hline Cefoxitin & Intramuscular & $22 \cdot 5$ & Kosmidis et al (1973) \\
\hline Cephacetrile & Intramuscular & $22 \cdot 7$ & Hodges et al (1973) \\
\hline Cephalexin & Oral & 32 & Griffith and Black (1968) \\
\hline Cephaloridine & Intramuscular & 27 & Turck et al (1967) \\
\hline Cephalothin & Intramuscular & $22 \cdot 8$ & Klein et al (1964) \\
\hline Cephanone & Intramuscular & $56 \cdot 6$ & Meyers et al (1972) \\
\hline Cephapirin & Intramuscular & 24 & Axelrod et al (1972) \\
\hline Cephradine & Oral & $24 \cdot 2$ & Zaki ot al (1974) \\
\hline
\end{tabular}

Table III Mean peak blood levels of cephalosporins after $1 \mathrm{~g}$ dose

shows that we are dealing with a normal, symmetrically distributed population of organisms.

\section{Discussion}

The results obtained here closely resemble those reported in similar studies, carried out in the USA and involving only a few cephalosporins, by Toala $e t$ al (1969) and Matsen and Coghlan (1972). Sensitivity patterns of enterococci thus appear to be similar on each side of the Atlantic. Seneca (1973), in a more recent survey of the activity of seven cephalosporins against organisms isolated from the urinary tract, confined his attention to Gramnegative organisms, so the present study supplements his. Our results confirm the two statements referred to in the introduction, that cephacetrile is more active than cephalothin, and cephradine than cephalexin, against enterococci, but the clinical significance of such facts is of extremely dubious significance, due to the high values of the MIC observed.

Two further cephalosporins which have proceeded as far as pharmacokinetic studies in man are cephanone and cephapirin. We were unable to test these compounds, but other workers have shown that their activity against enterococci is akin to that of cephalothin (Axelrod, Meyers, and Hirschman, 1971; Meyers, Hirschman, and Nicholas, 1972). Thus, none of the newer cephalosporins tested appear to show outstanding activity against enterococci, and none remotely approach ampicillin in this respect. Before dismissing these compounds, however, it is important to compare MICs with therapeutically attainable concentrations (table III). From these figures it can be seen that serum antibiotic levels inhibitory to enterococci are likely to be attainable in vivo for cephaloridine, cefazolin, and cephanone, and possibly for cephacetrile as well. When urinary concentrations are considered an entirely different picture emerges; due to the relatively short half-lives of the cephalosporins in man, urinary excretion of a given dose is virtually com- plete after about six hours, so that average concentrations in the urine over this period can be expected to be of the order of $2 \mathrm{mg} / \mathrm{ml}$ after a $1 \mathrm{~g}$ dose. Such concentrations of any of the antibiotics tested here would be inhibitory for all the enterococci tested. Choice of treatment for infections of the biliary tract must take into account that, of the compounds tested, only cefazolin and ampicillin are excreted to any substantial degree in the bile.

For one specific enterococcal infection, subacute endocarditis, combination therapy with benzylpenicillin and streptomycin is favoured by clinicians (Standiford, de Maine, and Kirby, 1970). Such a regimen may well be hazardous if the patient allergic to penicillins, and the markedly lower. incidence of reactions in such patients to cephalo? sporins makes the latter an attractive potentiäl alternative (Simon, 1967). On the basis of the findings in the present paper, a study of synergism between aminoglycosides on one hand, and cephaloridine, cefazolin, and cephanone on the other, may give valuable guidelines to alternative treatment regimens for systemic enterococcal infections in the penicillin-sensitive patient.

\section{References}

Axelrod, J., Meyers, B. R., and Hirschman, S. Z. (1971). Cephapirin : in vitro antibacterial spectrum. Appl. Microbiol., 22, 904-908.

Axelrod, J., Meyers, B. R., and Hirschman, S. Z. (1972). Cephapirin : pharmacology in normal human volunteers. J. clin. Pharmacol., 12, 84-88.

Cowan, S. T., and Steel, K. J. (1965). Manual for the Identification of Medical Bacteria. Cambridge University Press, Cambridge.

Cruickshank, R. (1968). Medical Microbiology, 11 th ed. Livingstone, N Edinburgh.

Facklam, R.R., and Moody, M. D. (1970). Presumptive identification of group D streptococci : the bile-esculin test. Appl. Microbiol., O 20, $245-250$.

Garrod, L. P., Lambert, H. P., and O'Grady, F. (1973). Antibiotic $W$ and Chemotherapy, 4th ed. Churchill Livingstone, Edinburgh $\underset{-}{\sigma}$ and London.

Gold, J. A., McKee, J. J., and Ziv, D. S. (1973). Experience with cefazolin: an overall summary of pharmacologic and clinical trials in man. J. infect. Dis., 128, S., 415-421.

Griffiths, R. S., and Black, H. R. (1968). Cephalexin: a new antibiotic. Clin. Med., 75, 14-22.

Hamilton-Miller, J. M. T., and Brumfitt, W. (1974). Newer $\beta$-lactam antibiotics-a review. Infection, 2, 82-94.

Hodges, G. R., Scholand, J. F., and Perkins, R. L. (1973). Cephace- 
trile: clinical evaluation in 27 patients. Antimicrob. Agents and Chemother., 3, 228-234.

Isenberg, H. D., Painter, B. G., Sampson-Scherer, J., and Siegel, M. (1973). Clinical laboratory study of cephacetrile and cephalothin against bacteria recently isolated from clinical specimens. Amer. J. clin. Path., 59, 700-705.

Klein, J. O., Eickhoff, T. C., Tilles, J. G., and Finland, M. (1964). Cephalothin: activity in vitro, absorption and excretion in normal subjects and clinical observations in $\mathbf{4 0}$ patients. Amer. J. med. Sci., 248, 640-656.

Kosmidis, J., Hamilton-Miller, J. M. T., Gilchrist, J. N. G., Kerry, D. W., and Brumfitt, W. (1973). Cefoxitin, a new semisynthetic cephamycin: an in-vitro and in-vivo comparison with cephalothin. Brit. med. J., 4, 653-655.

Luria, S. E. (1960). The bacterial protoplasm: composition and organisation. In The Bacteria, edited by I. C. Gunsalus and R. Y. Stanier, vol. 1, pp. 1-34. Academic Press, New York and London.

Matsen, J. M., and Coghlan, C. R. (1972). In Streptococci and Streptococcal Disease, edited by L. L. Wannamaker and J. M. Matsen. Academic Press, New York and London.

Meyers, B. R., Hirschman, S. Z., and Nicholas, P. (1972). Cephanone: in vitro activity and pharmacology in normal human volun- teers. Antimicrob. Agents and Chemother., 2, 250-254.

Neiss, E. S. (1973). Cephradine: a summary of preclinical (and clinical) studies and clinical pharmacology. J. Irish med. Ass., Suppl., 66, 1-12.

Seneca, H. (1973). Drug susceptibility/resistance pattern of gramnegative uropathogens to seven cephalosporins. Amer. J. med. Sci., 266, 381-385.

Simon, H. J. (1967). Antimicrobial susceptibility of group D hemolytic streptococci (enterococci). Amer. J. med. Sci., 253, 14-18.

Standiford, H. D., de Maine, J. B., and Kirby, W. M. M. (1970). Antibiotic sensitivity of enterococci: relation to inhibitory concentrations. Arch. intern. Med., 126, 255-259.

Toala, P., McDonald, A., Wilcox, C., and Finland, M. (1969). Susceptibility of group D Streptococcus (Enterococcus) to 21 antibiotics in vitro, with special reference to species differences. Amer. J. med. Sci., 258, 416-430.

Turck, M., Belcher, D. W., Ronald, A., Smith, R. H., and Wallace, J. F. (1967). New cephalosporin antibiotic-cephaloridine. Arch. intern. Med., 119, 50-59.

Zaki, A., Schreiber, E. C., Weliky, I., Knill, J. R., and Hubsher, J. A. (1974). Clinical pharmacology of oral cephradine. J. clin. Pharmacol., 14, 118-126. 